\title{
Epilepsy surgery for refractory seizures: a systematic review and meta-analysis in different complications
}

\author{
Maryam Joudi Mashhad ${ }^{1}$, Hadi Harati ${ }^{2}$, Fateme Parooie ${ }^{3}$ and Morteza Salarzaei ${ }^{3^{*}}$
}

\begin{abstract}
Background: Nearly one-third of epilepsy patients are refractory/resistant to medical treatment. Developments made in surgical techniques have significantly increased the effectiveness and safety of these techniques, as such techniques have been demonstrated to improve seizure control/freedom outcomes.

Objectives: The aim of this systematic review and meta-analysis was to evaluate the complications of epilepsy surgery.

Patient and methods: The searches were conducted by three independent researchers to find the relevant studies published from January 1, 2009, until the end of January 6, 2019. For English published statistical studies, all studies conducted on epileptic patients who have undergone epilepsy surgery were included.

Statistical analysis: A meta-analysis was conducted in the STATA14 statistical software.

Results: A total of 6735 patients with epilepsy who had undergone the epilepsy surgery were studied. The overall prevalence of complications was 5\%. The prevalence of major and minor complications was $5.4 \%$ and 3.2\% respectively. The prevalence of complications related to the temporal epilepsy surgery and the extra-temporal epilepsy surgery based on 3 studies was $7.9 \%$ and $8.2 \%$ respectively. The frequency of neurological and surgical complications after epilepsy surgery was $4.4 \%$ and $4.1 \%$ respectively.

Conclusion: The overall rate of complications caused by epilepsy surgery was reasonably low (5\%), implying that epilepsy surgery especially temporal lobe resection can be safe preferably when performed by an experienced surgeon.
\end{abstract}

Keywords: Refractory epilepsy, Epilepsy surgery, Complication, Seizure, Temporal lobe resection

\section{Introduction}

Nearly one-third of epilepsy patients are refractory/resistant to medical treatment [1]. Refractory or drug-resistant epilepsy is defined as resistance to treatment with two appropriately chosen and tolerated antiepileptic drugs (AED) [2]. Nevertheless, epilepsy surgery is an effective alternative treatment for some patients as it suggests seizure freedom $[3,4]$. During the past 3 decades, surgery has

\footnotetext{
* Correspondence: zhn.search@gmail.com

${ }^{3}$ Student Research Committee, Zabol University of Medical Sciences, Zabol, Iran

Full list of author information is available at the end of the article
}

found more acceptance as an option for drug-resistant epilepsy [5]. Developments made in surgical techniques have significantly increased the effectiveness and safety of these techniques, as such techniques have been demonstrated to improve seizure control/freedom outcomes [6] and enhanced quality of life in patients [7]. Neuroimaging developments with the introduction of positron emission tomography (PET), magnetic resonance imaging (MRI), functional MRI, single-photon emission computed tomography (PET-CT), and magnetoencephalography have facilitated the presurgical evaluation of patients, thus providing the lesion-directed surgeries more possible [8], 
also reducing the number and severity of complications [9]. Complications of epilepsy surgery including failure to stop seizures and neuropsychological, psychosocial, or psychiatric impairment are still difficult to define, and there is no universal consensus in this regard. A few studies which were conducted on single centers have reported the risk of the development of complications during the presurgical evaluation processes and various therapeutic surgical procedures [10-13]. However, the major complications of epilepsy surgery that have been well-documented include cerebral infarction, hematoma formation, mass effect due to cerebral edema, infection, and even death [14-17]. Also, given the fact that major complications are almost always accompanied with this type of surgery, the surgeon should consider the occurrence of such complications in order to improve the assessment of risk/benefit ratio as an essential criterion for planning epilepsy surgery and encouraging patients [18]. Risk perception is one of the main factors affecting the patient's decision to undergo epilepsy surgery [19]. In fact, the use of epilepsy surgery has been gradually declining in the USA, recently [20]. Even though the risks associated with persistent medical intractability should be weighed against the risks of surgery, one possible explanation for underutilization of epilepsy surgery is the lack of awareness of the actual risks caused by epilepsy surgery. Such knowledge gap can affect the number of referrals in two ways: Epileptologists' over/ under-estimation of the complications of epilepsy surgery may discourage them to perform surgery when it is needed or cause inevitable complications by doing an un-necessary surgery. Furthermore, as surgical techniques improve and risks decrease, epileptologists may make decisions based on their past experience of high complication rates and thus by overestimating the complication rates in the modern neurosurgical era [21].The main purpose of this systematic review and meta-analysis is to assess the complications of epilepsy surgery.

\section{Method}

The methods used in this systematic review were developed in accordance with the PRISMA checklist instructions [22]. Cross-sectional, case-control, and cohort studies were included and the case series, letter to editors, case reports, clinical trials, study protocols, systematic reviews, and narrative reviews were excluded.

\section{Participants}

All studies conducted on epileptic patients who have undergone epilepsy surgery were included. By definition, refractory epilepsy was considered as disabling seizures occurring with a frequency of at least 2 per month for a period of more than 2 years, despite treatment with at least 2 antiepileptic drugs either in combination or successive monotherapies in optimum/tolerated doses.

\section{Output}

The main goal was to find the prevalence of complications of epilepsy surgery, and the output was collected as it was reported.

\section{Sampling techniques and sample size}

All observational studies were included in the systematic review regardless of their design. The minimum sample size was greater than or equal to 25 (patients). A complication was defined as an uncommon, unexpected, or unwanted event after a procedure. Surgical complications referred to events related to surgery specifically including infection, hematoma, deep vein thrombosis, pulmonary embolism, hydrocephalus, CSF leakage, brain edema, and neurological complications were consisted of hemi/monoparesis, sensory deficit, hemianopia, cranial nerve effects, and dysphasia. The severity of a complication is graded as minor or major in accordance with previous validated articles. A complication has been defined as minor if it resolves within 3 months and major if it affects activities of daily living and lasts longer than 3 months. Major complications also include any significant neurological deficits, even if they do not affect activities of daily living. An infected bone flap that requires cranioplasty later is defined as minor, even if the cranial defect persists longer than 3 months.

The searches were conducted by three independent researchers (MS, HH, FP) to find the relevant studies published from January 1, 2009, until the end of January 6, 2019. We searched for published literature in English language in Medline via PubMed, embasetm via ovid, Cochrane library, and Trip database.

For literature published in other languages, we searched national databases (Magiran and SID), Korea med and lilacs. Also, open grey (www.opengrey.eu/) and the World Health Organization clinical trials registry (who.int/ictrp) were searched for finding unpublished literature and ongoing studies. A list of the included research references and relevant reviews prepared by searching was analyzed to evaluate the literature saturation (FP, MJ). The special search strategies were developed through the Health Sciences Librarian website that is specialized in systematic review searches using the $\mathrm{MeSH}$ and open phrases in line with the "Press" standards [23]. After finalizing "Medline" strategy, the results were compared in order to search the other databases. Similarly, "Prospero" was searched to find the recent or ongoing systematic reviews. The keywords used in the search strategy were "epilepsy surgery, temporal lobe epilepsy, complication, major complication, extra temporal epilepsy, temporal resection, surgical complication, neurological complication, refractory seizure" which were combined using "and", "or", and "not" operators.

Two researchers independently analyzed the titles and abstracts of the articles considering research eligibility 
criteria (HH, FP). After omitting the redundant studies, the full texts of the studies were assessed to have the eligibility criteria, and the information of the authors was collected when required. General information (the corresponding author, province, and year of publication), the study information (the sampling technique, information collection method, research conditions, sample size, and risk of bias), and the output scales (prevalence of epilepsy surgery complication) were collected.

The scale developed by Hoy and colleagues [24] was used to assess the quality of the methodology and the risk of bias for each observational study. This 10 -item scale is used to assess the quality of the studies in accordance with their external validity (items 1 to 4 assess the target population, sampling framework, and minimum participation bias) and internal validity (items 5 to 9 assess the data collection method, problem statement, research scale, and data collection instruments while item 10 assesses the data analysis bias). The risk of bias was measured independently by two researchers (MS, MJ), and the differences were solved by reaching a consensus.

All of the eligible studies were included in the data aggregation following a systematic review, and the data was integrated using a forest plot. The random effects model was assessed based on the overall epilepsy surgery complications. The heterogeneity of the preliminary studies was tested using the " 2 " test. Besides, the subgroups were analyzed to determine the heterogeneity based on the prevalence of epilepsy complications, year of publication, age of the participants, and female to male ratio of participants. Finally, a metaanalysis was conducted in the STATA14 statistical software.

\section{Results}

A total of 273 articles were extracted through our preliminary searches (261 through database searching and 12 through other sources). Of the 273 studies identified by analyzing the titles and abstracts, 32 studies were excluded due to duplication. Of the existing 241 studies, 169 articles were excluded with reasons. Of the 169 excluded studies, 48 did not have full text, 18 were review articles, 9 were letter to editor, and 43 did not meet the minimum inclusion criteria. From the 72 remaining studies, 18 studies met the inclusion criteria (Fig. 1).

A total of 6735 patients with epilepsy who had undergone epilepsy surgery were studied. The age of the participants varied between 2 months to 90 years. All studies, presented retrospective data.

A total number of 18 studies from 14 countries, which had the inclusion criteria, were reviewed. Of these 18 studies, three studies were from the USA [25-27], three were from Turkey [28-30], two studies were from Sweden [31, 32] and Germany [27, 32-40]; Thailand [41], Mexico [42], UK [43], Korea [34], Italy [35], Belgium [36], France [37], India [38], and Canada [39] each had one study included. The common sampling technique was convenience sampling $(n=18)$. Eighty percent of the studies had low risk of bias. The most prevalent data collection methods were the Medical records, self-report, and

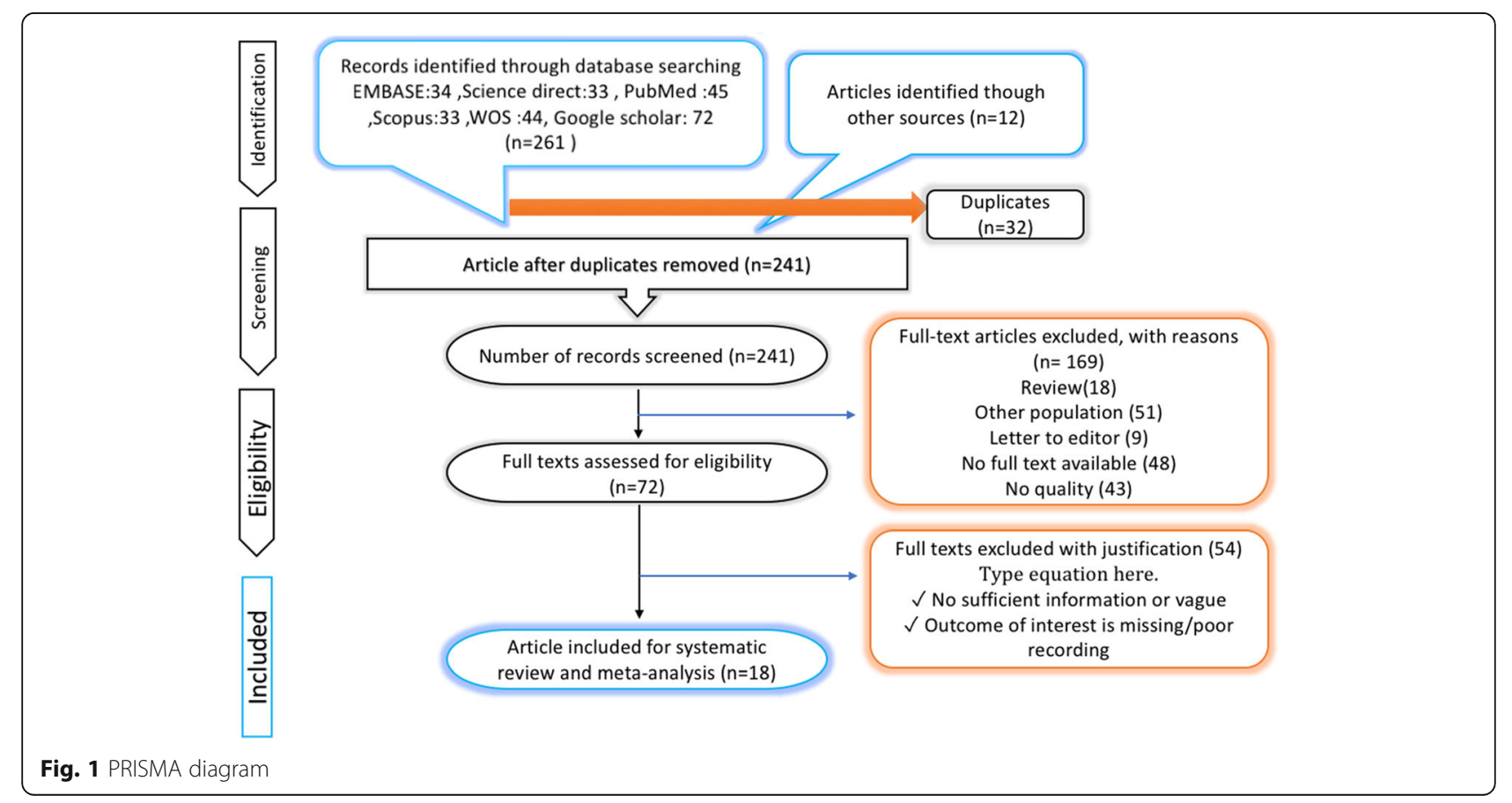


interview methods. The most common study locations were hospitals $(n=18)$ (Table 1$)$.

Based on the random effect model, the total prevalence of complications in 6735 patients with epilepsy who had undergone the epilepsy surgery was 5\% (95\% CI $4.5-5.5 \%, I^{2}=96.9 \%$ ) (Fig. 2).

\section{Meta-analysis of overall seizure-free outcome after epilepsy surgery}

Based on the random effect model 73\% (95\% CI 70$\left.75 \%, I^{2}=95.3 \%\right)$ of 854 patients who had undergone epilepsy surgery became seizure-free (Fig. 3). Seizurefreedom was defined based on Engel class 1a, seizure free or only auras since surgery.
The frequency of complications after temporal epilepsy surgery was $7.9 \%$ (95\% CI $\left.6.4-9.4 \%, I^{2}=94 \%\right)$ based on 3 studies among 1270 participants (Fig. 4a), and the frequency of extra-temporal epilepsy surgery complications based on 3 studies among 643 participants was $8.2 \%$ (95\% CI 6.1-10.2\%, $I^{2}=95.9 \%$ ) (Fig. 4b).

The frequency of neurological complications after epilepsy surgery was $4.4 \%\left(95 \%\right.$ CI $\left.3.8-5.1 \%, I^{2}=94.8 \%\right)$ based on 8 articles among 3700 participants [44, 45] (Fig. 5a), and the frequency of surgical complications after epilepsy surgery was $4.1 \%\left(95 \%\right.$ CI $3.2-5 \%, I^{2}=88 \%$ ) based on 7 articles among 1795 participants (Fig. 5b)

Based on the random effect model, the total prevalence of minor complications in 4493 patients who had

Table 1 Study characteristics

\begin{tabular}{|c|c|c|c|c|c|c|c|c|c|}
\hline Author & Year & $\begin{array}{l}\text { Country/ } \\
\text { province }\end{array}$ & $\begin{array}{l}\text { Sampling } \\
\text { method }\end{array}$ & Study design & $\begin{array}{l}\text { Study } \\
\text { duration }\end{array}$ & $\begin{array}{l}\text { Female to } \\
\text { male }\end{array}$ & Participants & $\begin{array}{l}\text { Age mean } \pm S D \\
\text { or range }\end{array}$ & $\begin{array}{l}\text { Seizure free } \\
\text { (Engel class 1a) }\end{array}$ \\
\hline Vale et al. [25] & 2013 & USA & Convenience & Retrospective & $\begin{array}{l}1998- \\
2012\end{array}$ & 1.04 & 483 & $4-75(36.7)$ & N/A \\
\hline Srikijvilaikul [41] & 2018 & Thailand & Convenience & Retrospective & $\begin{array}{l}2011- \\
2015\end{array}$ & 0.98 & 194 & $27.9 \pm 15.1$ & N/A \\
\hline $\begin{array}{l}\text { Espinoza-Velázquez et al. } \\
\text { [42] }\end{array}$ & 2014 & Mexico & Convenience & Retrospective & $\begin{array}{l}1992- \\
2013\end{array}$ & N/A & 227 & N/A & N/A \\
\hline Ozlen et al. [28] & 2010 & Turkey & Convenience & Retrospective & $\begin{array}{l}2004- \\
2009\end{array}$ & 1.33 & 70 & $23.4 \pm 11.9$ & N/A \\
\hline Ipekdal et al. [29] & 2010 & Turkey & Convenience & Retrospective & $\begin{array}{l}2000- \\
2010\end{array}$ & 2.5 & 58 & $25-45(33.3)$ & N/A \\
\hline Ahmedo et al. [30] & 2018 & Turkey & Convenience & Retrospective & $\begin{array}{l}2009- \\
2017\end{array}$ & 0.96 & 53 & 19-55 (30.4 \pm 9$)$ & N/A \\
\hline Hedegard et al .[31] & 2013 & Sweden & Convenience & Retrospective & $\begin{array}{l}1996- \\
2010\end{array}$ & 0.94 & 271 & $2-58(26)$ & $\mathrm{N} / \mathrm{A}$ \\
\hline Dunkley et al .[43] & 2010 & UK & Convenience & Retrospective & -- & 0.75 & 42 & $\begin{array}{l}3-36 \text { months ( } 20 \\
\text { months) }\end{array}$ & $48 \%(20)$ \\
\hline Heller et al .[26] & 2009 & USA & Convenience & Retrospective & $\begin{array}{l}1998- \\
2005\end{array}$ & N/A & 190 & N/A & N/A \\
\hline Binder et al .[33] & 2009 & Germany & Convenience & Retrospective & $\begin{array}{l}1990- \\
2004\end{array}$ & 1.35 & 40 & 25 & $57.5 \%(23)$ \\
\hline Lee et al .[34] & 2009 & Korea & Convenience & Retrospective & $\begin{array}{l}1997- \\
2006\end{array}$ & 0.84 & 92 & 3 months-36 years & N/A \\
\hline d'Orio et al .[35] & 2017 & Italy & Convenience & Retrospective & $\begin{array}{l}1997- \\
2014\end{array}$ & 0.43 & 50 & $50-62(53.8)$ & $78 \%(39)$ \\
\hline Bjellvi et al. [32] & 2015 & Sweden & Convenience & Retrospective & $\begin{array}{l}1996- \\
2015\end{array}$ & 0.95 & 865 & $\begin{array}{l}2 \text { months }-69 \text { years } \\
(24)\end{array}$ & N/A \\
\hline Rolston et al. [27] & 2016 & USA & Convenience & Retrospective & $\begin{array}{l}2000- \\
2013\end{array}$ & 1.02 & 6200 & $18-90(45.6 \pm 16.8)$ & N/A \\
\hline Vermeulen et al. [36] & 2016 & Belgium & Convenience & Retrospective & $\begin{array}{l}1998- \\
2012\end{array}$ & 1.14 & 199 & $14-64(40)$ & $77 \%(153)$ \\
\hline Mathon et al. [37] & 2017 & France & Convenience & Retrospective & $\begin{array}{l}1990- \\
2015\end{array}$ & 1.11 & 389 & $(36.7)$ & $83.7 \%(302)$ \\
\hline Panigrahi et al .[38] & 2016 & India & Convenience & Retrospective & - & 0.75 & 697 & $30.4 \pm 12.4$ & $N / A$ \\
\hline Tanriverdi et al. [39] & 2009 & Canada & Convenience & Retrospective & & 1.02 & 1905 & $(30.4)$ & N/A \\
\hline Wellmer et al. [40] & 2012 & Germany & Convenience & Retrospective & $\begin{array}{l}2002- \\
2008\end{array}$ & 0.75 & 502 & $\mathrm{~N} / \mathrm{A}$ & $49.7 \%(82)$ \\
\hline
\end{tabular}




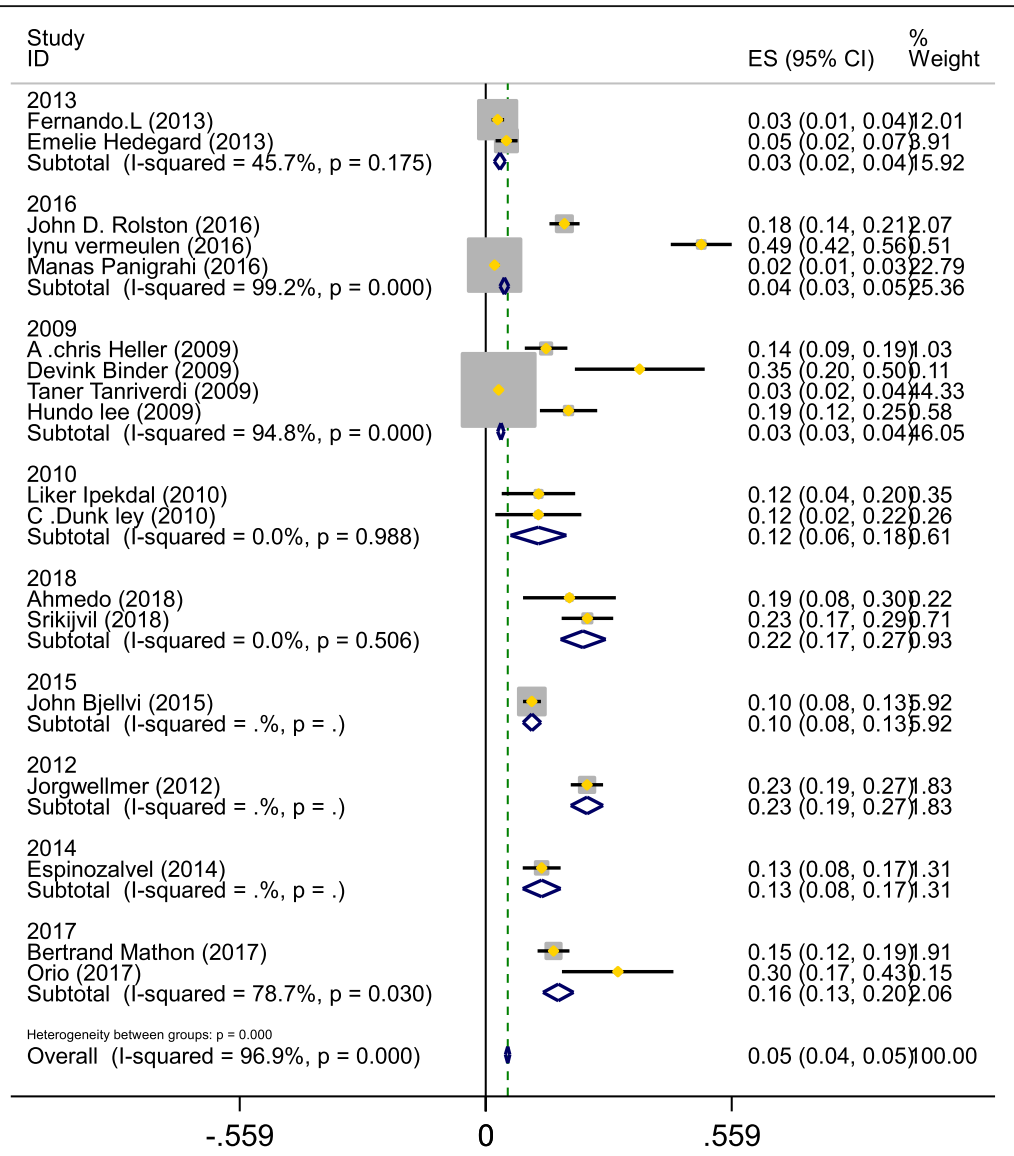

Fig. 2 Meta-analysis of overall prevalence of epilepsy surgery complications

undergone the epilepsy surgery was 3.2\% (95\% CI $2.7-$ $3.7 \%, I^{2}=91.4 \%$ ) and the total prevalence of major complications in 2317 patients who had undergone the epilepsy surgery was $5.4 \%$ (95\% CI $\left.4.9-5.9 \%, I^{2}=92.3 \%\right)$ (Fig. 6a, b).

The frequency of epilepsy surgery complications was the most in Belgium (49\%) based on one conducted study [36], followed by Italy (30\%) based on one study [35], Germany (23.7\%) based on two studies [33, 40], Thailand (23.1\%) based on one study [41], Korea (18.8\%) based on one study [34], France (15.4\%) based on one study [37], Turkey (14.7\%) based on three studies [2830], Mexico (12.7\%) based on one study [42], UK (11.9\%) based on one study [43], Sweden (8.2\%) based on two studies [31, 32], USA $(5.5 \%)$ based on one study, Canada (2.9\%) based on one study [39], and India (2\%) based on one study [38], respectively (Fig. 7).

\section{Meta-analysis of neurological epilepsy surgery complications based on the country}

The frequency of neurological epilepsy surgery complications was the most in Belgium (37\%) based on one conducted study [36], followed by Italy (20\%) based on one study [35], Thailand (11\%) based on one study [41], Sweden (6.5\%) based on two studies [31, 32], Turkey (5.8\%) based on three studies [28-30], France (3.9\%) based on one study [37], and Canada (3.2\%) based on one study [39], respectively (Fig. 8a).

\section{Meta-analysis of surgical complications of epilepsy surgery based on the country}

The frequency of surgical complications of epilepsy surgery was the most in Thailand (15.6\%) based on one study followed by Turkey (13.2\%) based on two studies, Belgium (12\%) based on one conducted study [44, 45], and Italy $(10 \%)$ based on one study, respectively (Fig. $8 b)$.

Meta-regression between year of the publication, female to male ratio, and age of the participants and prevalence of epilepsy surgery complications:

The studies' meta-regression was based on the association between prevalence of epilepsy surgery complications and the publication year of the studies, female to male ratio, and age of the participants. There was no statistically significant linear trend in univariate meta- 


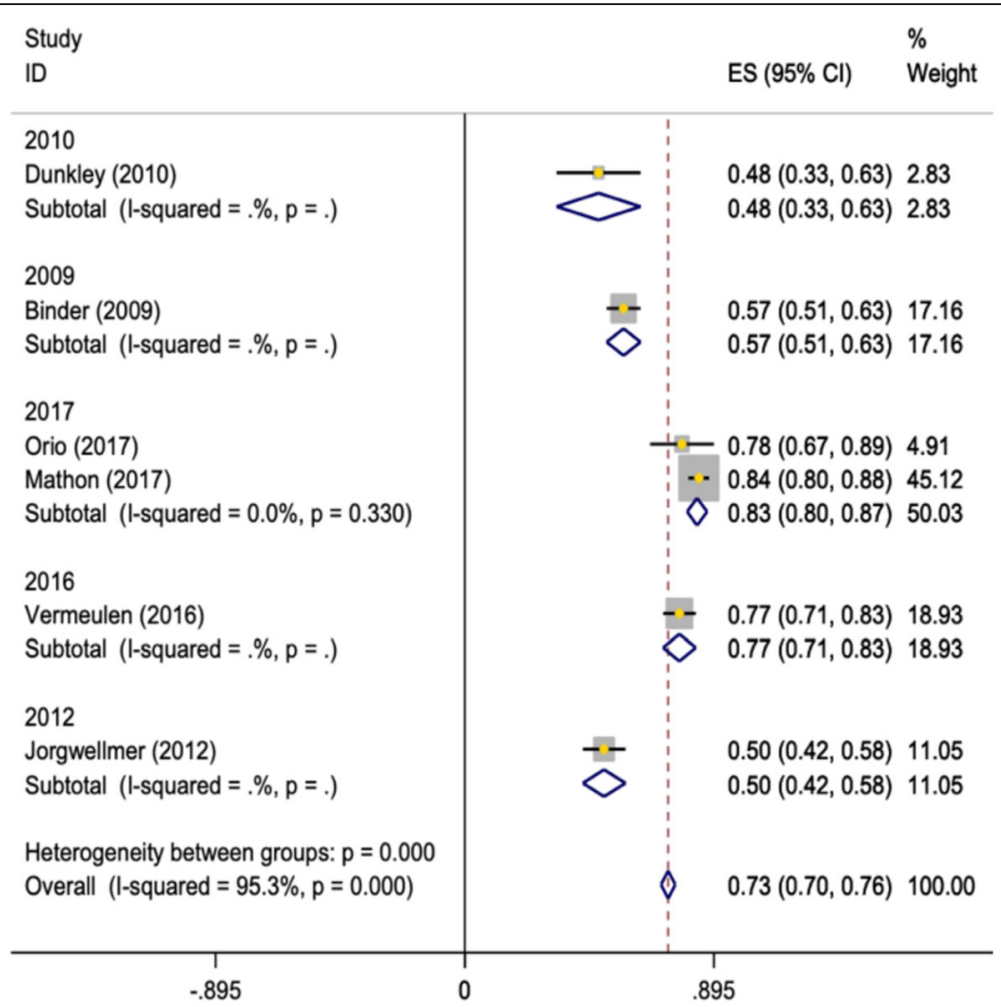

Fig. 3 The overall seizure-free outcome after epilepsy surgery

regression to explain effect size variation by publication year of study or female to male ratio or age of the participants (Fig. 9).

Funnel plot in Fig. 9 shows no indication of publication bias. It is shown in funnel plot symmetrically. Circles' sizes show the weight of studies (bigger circles show more sample and smaller circles show fewer sample) (Fig. 9d).

\section{Discussion}

Nearly two-thirds of patients with medically refractory temporal lobe epilepsy are released from long-term seizure in the postoperative phase [46-50]. The results of a previous review showed that $44 \%$ of the patients undergoing temporal lobe surgery were found to be seizure free [51]. After epilepsy surgery, a range of medical and neurological complications and side effects are likely to

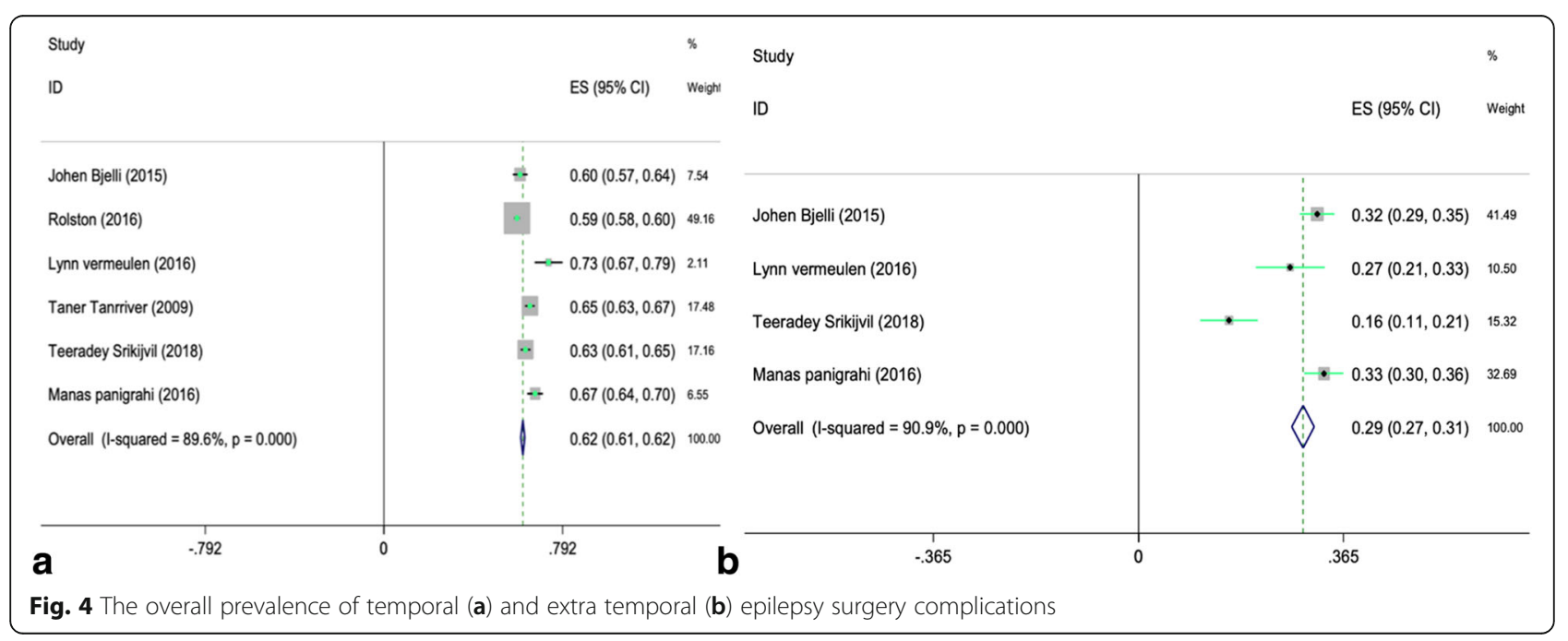




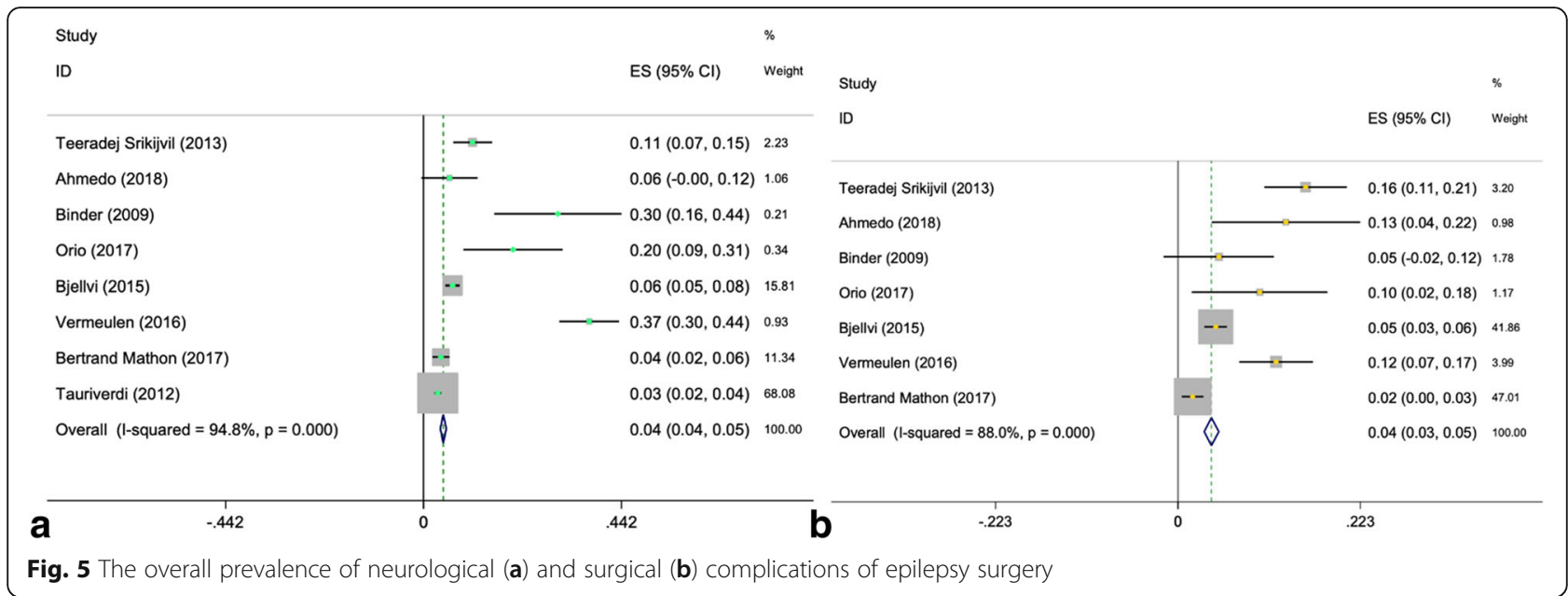

develop, which are caused by both invasive monitoring for localization of the epileptic focus or after definitive resective procedures taken for removing the epileptogenic focus. Patients and physicians' concern for the perceived risks associated with surgery may prevent appropriate candidates from pursuing epilepsy surgery evaluation. However, the results of a systematic review and meta-analysis conducted by Seiam and colleagues emphasized the significant improvement in quality of life (QOL) in adults undergoing epilepsy surgery [52]. The present study attempts to provide some insights for patients and physicians about the risks associated with epilepsy surgery, and consequently, they can make the best decision about performing the surgery. Besides, this study aims to discredit the misconceptions about the dangerous nature of this type of surgery. The failure to perform epilepsy surgery for eligible patients may prevent an effective treatment for providing seizure freedom, improved quality of life, and reduced risk of premature mortality caused by intractable epilepsy for most patients [53]. In spite of the effectiveness of surgical interventions for treating intractable epilepsy, the possibility of offering surgery to potential candidates is nearly $58 \%[54,55]$. There are various factors associated with this inadequate referral of patients [56]. Because of the lack of a clear definition of medical intractability, patients are likely to perceive epilepsy surgery is only for end-stage patients [57]. Neurologists can facilitate the enrollment of patients with intractable epilepsy in epilepsy surgery. Various factors including the type of surgery (invasive vs. resective), the location of resection (temporal vs. extratemporal), and the patient's age may affect the reported frequency and nature of specific side effects and complications induced by epilepsy surgery. In the present systematic review and meta-analysis, we analyzed the data provided in the previous studies from different aspects. Firstly, we provided an overall rate of complications between all 6735 participants undergoing

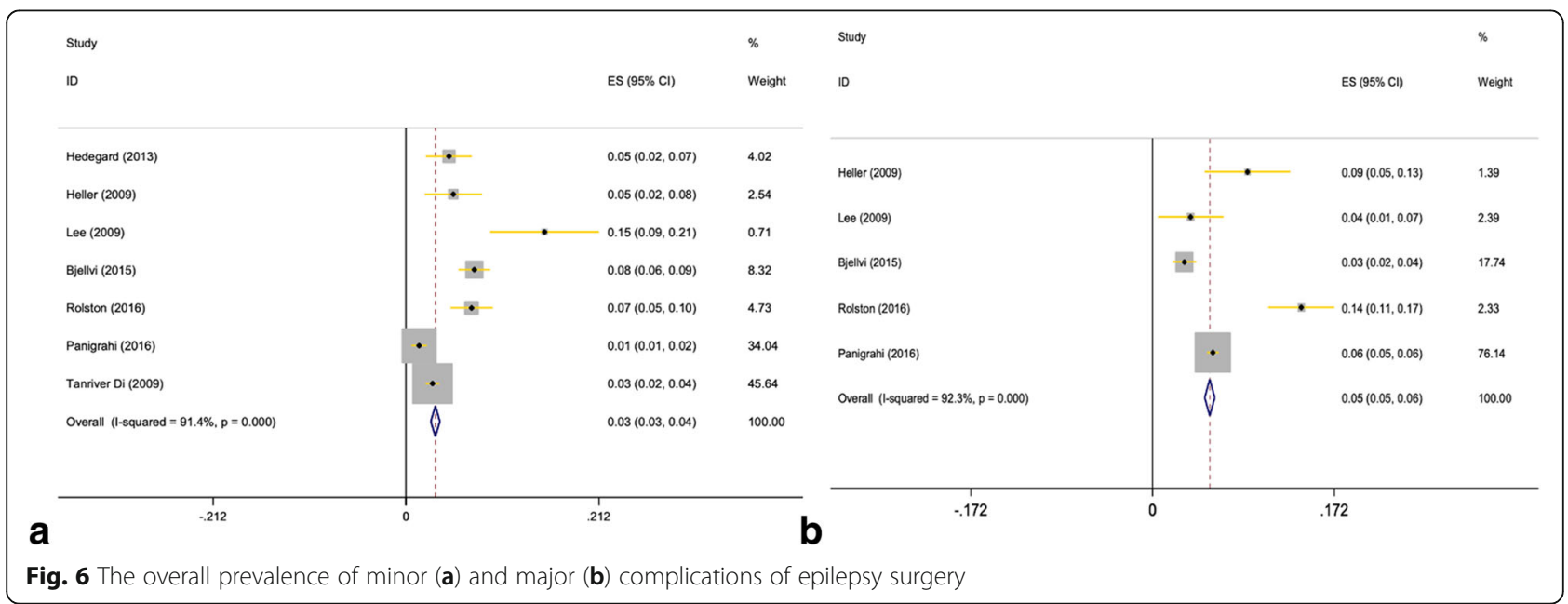




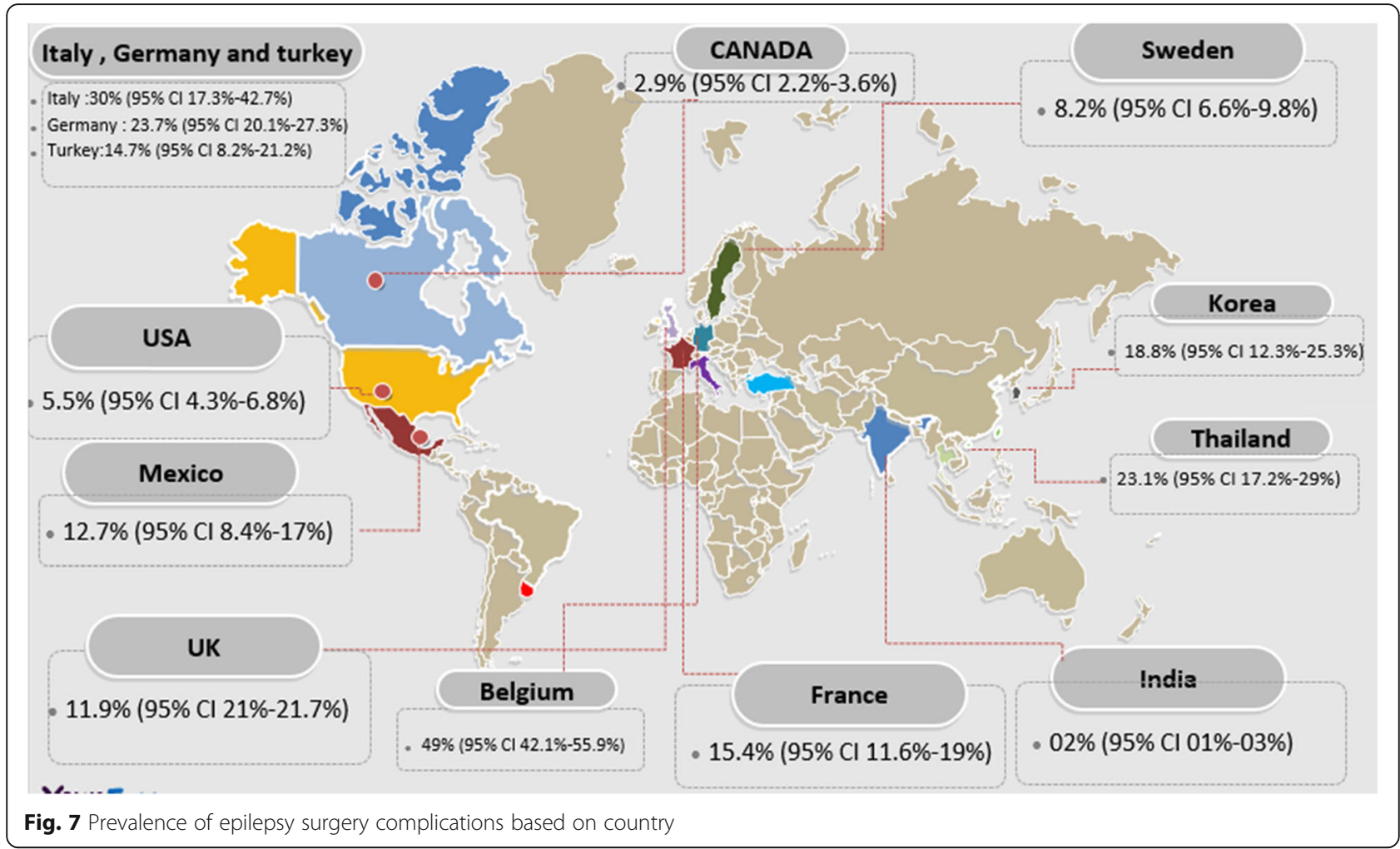

any kind of epilepsy surgery. Secondly, we calculated the prevalence of major and minor complications among 6810 patients and based on 5 and 7 studies which provided this data, respectively. After that, we analyzed the data based on the location of the surgery (temporal and extra temporal) among 1913 patients of 6 and 4 studies, respectively. Then, we demonstrated the prevalence of neurological and surgical complications of this surgery among 5495 patients based on 7 and 8 studies, respectively. We also provided the prevalence of overall complications of epilepsy surgery in each country. The present systematic review and meta-analysis demonstrated that the prevalence of overall complications of epilepsy surgery was $5 \%$. The overall prevalence of major and minor complications between 6810 participants was $5.4 \%$ and $3.2 \%$, respectively. For temporal lobe resection, as the most common procedure in epilepsy surgery (with a prevalence of $61.6 \%$ ), the overall rate of complications was $7.9 \%$ based on 3 articles. However, $5.4 \%$ of these complications were subdivided as minor, and $1.8 \%$ was major complications. The prevalence of overall complications in extra temporal epilepsy surgery based on 3 articles was $8.2 \%$ consisting of $6 \%$ minor and $2 \%$ major complications. Jobst and colleagues pointed to the greater efficacy of temporal lobe resection compared to medical treatment for medically refractory epilepsy. They also reported an outcome of $62.5 \%$ seizure-free
[44]. The most serious complications resulting from epilepsy surgery are the neurologic complications that negatively affect visual, motor, speech, and memory systems, with the potential to decrease long-term quality of life. The prevalence of neurological complications in this study was $4.4 \%$ (95\% CI $\left.3.8-5.1 \%, I^{2}=94.8 \%\right)$ among 3700 patients. Hader and colleagues in their systematic review and meta-analysis indicated that overall, minor medical complications were reported in $5.1 \%$ of patients, whereas major medical complications were identified in $1.5 \%$ [58]. Also, the prevalence of surgical complications in the present study was $4.1 \%\left(95 \%\right.$ CI $3.2-5 \%, I^{2}=$ $88 \%)$. The mortality rate of epilepsy surgery was reported to be $0 \%$ in most of the studies $[25,27-32,36$, 37, 39-43]; only studies conducted by Bjellvi and colleagues, Heller and colleagues, and Panigrahi and colleagues reported mortality rates of $0.5 \%, 0.52 \%$, and $0.14 \%$ respectively $[26,32,38]$. However, Hader and colleagues indicated a $0.4 \%$ rate of mortality in temporal lobe patients [58] which is quite consistent with the results of this study. Although epilepsy surgery seems to offer a very good seizure control with reasonably low morbidity rates, there is still insufficient clinical trial data to demonstrate non-seizure-related outcomes of epilepsy operations [45]. Despite the fact that this systematic review offers a comprehensive assessment of reported frequencies of complications associated with 


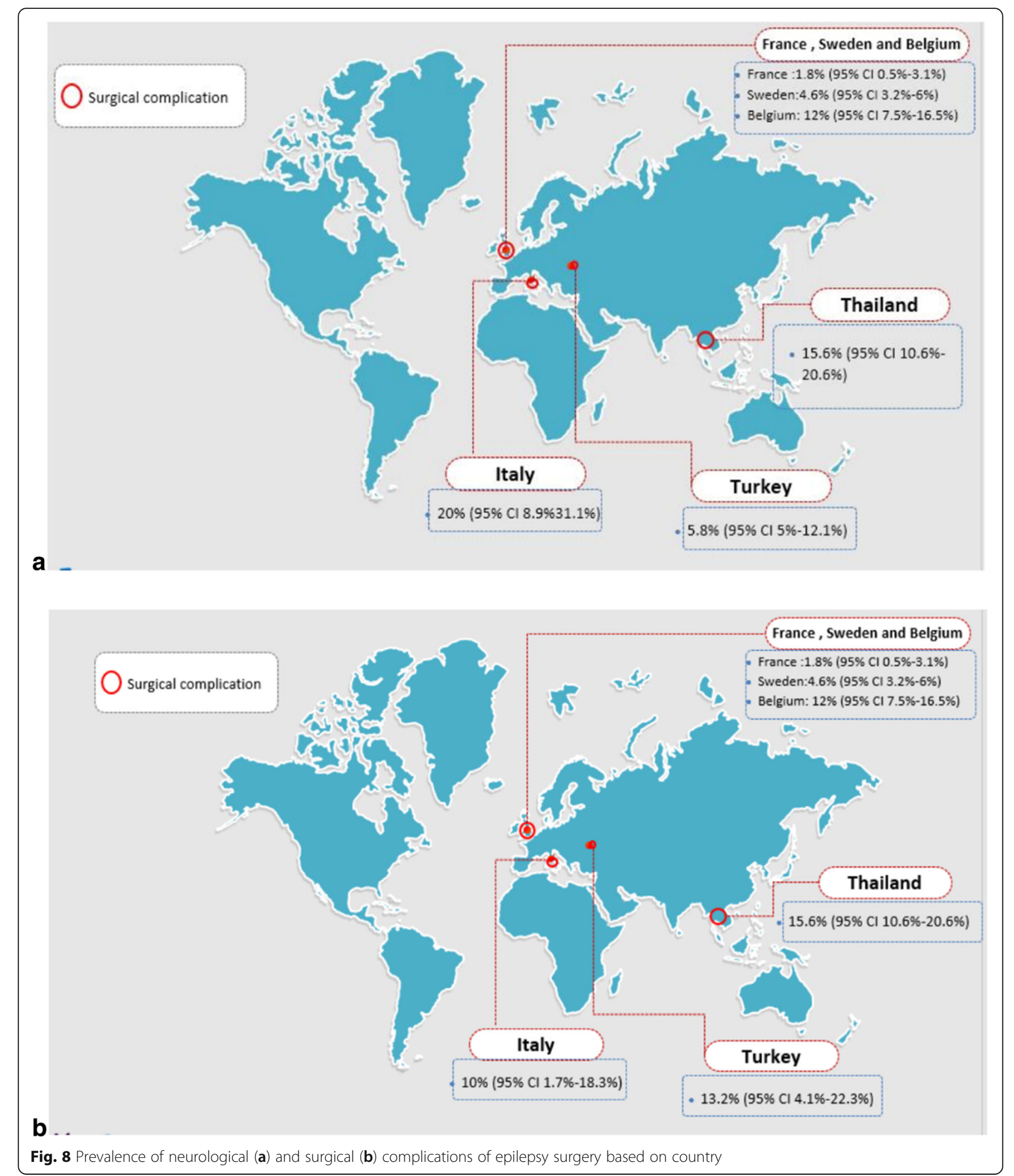

epilepsy surgery, there are several limitations. Although large randomized cases with multiple surgeons were assessed reflecting a more generalizable experience, the prevalence of complications is likely to depend on the surgeon who does the surgery and the epilepsy center.
In addition, the methods used for reporting complications showed considerable inconsistencies and reported frequencies in this review were determined from studies on different sample sizes that included multiple age groups with different locations of resections. 

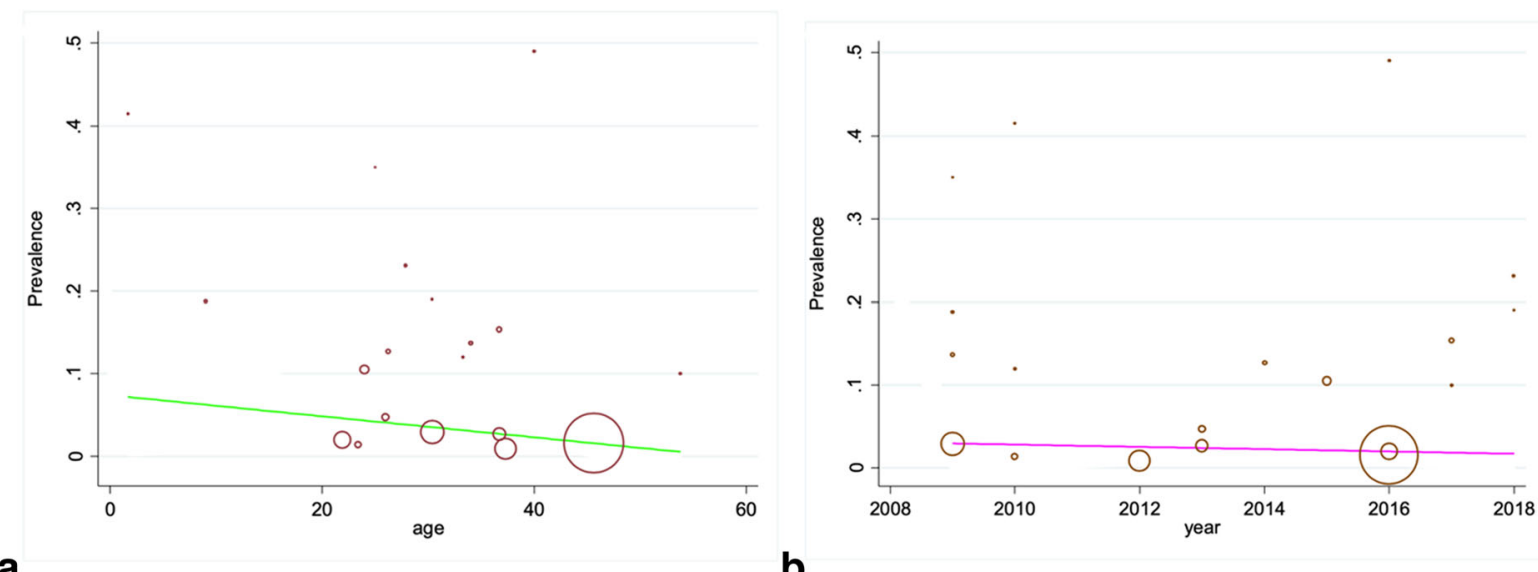

a

b
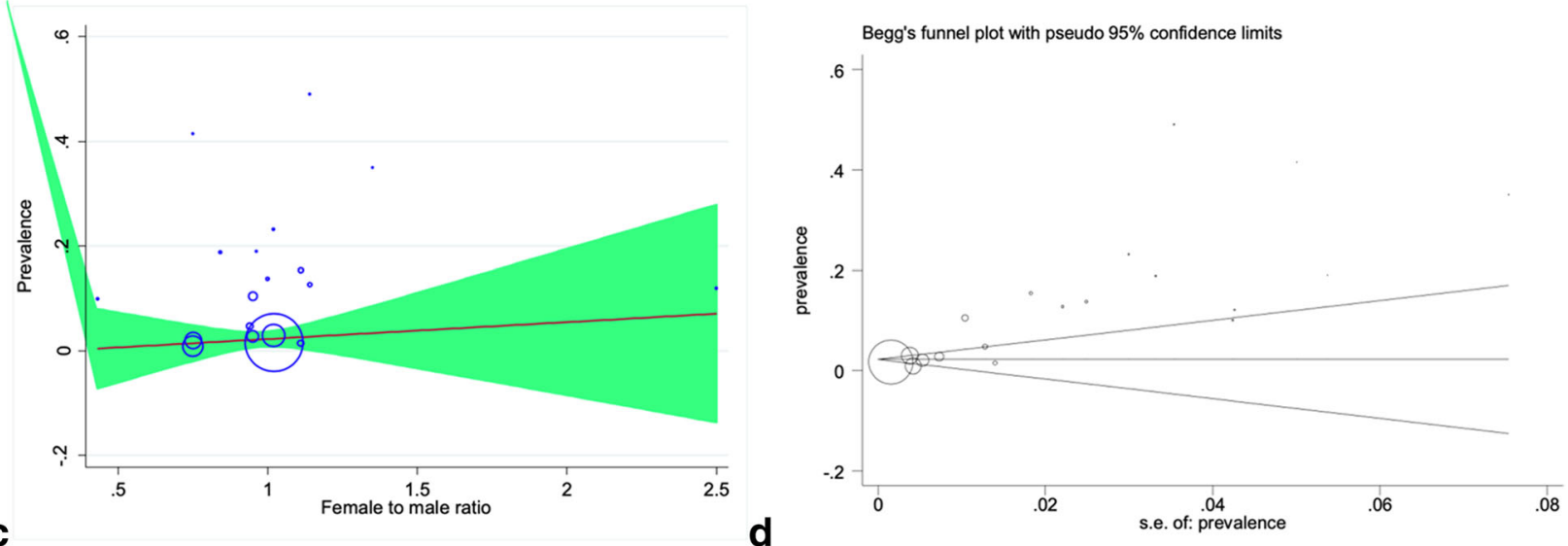

Fig. 9 Meta-regression between age (a) and sex(c) of the participants and publication year (b) and prevalence of epilepsy surgery complications. Begg's funnel plot (d)

\section{Conclusion}

The present systematic review and meta-analysis indicated that the overall rate of complications caused by epilepsy surgery was reasonably low (5\%), implying that epilepsy surgery especially temporal lobe resection can be safe preferably when performed by an experienced surgeon. The findings of this review have some implications for eliminating some concerns and misconceptions about epilepsy surgery. These findings can increase the possibility of referring more eligible candidates to specialized epilepsy centers for surgical evaluation. Epilepsy surgery outcomes offer a promising prospect and deserve further investigation. However, before performing more trials, patients and physicians need to be assured to consider epilepsy surgery for treating medically refractory seizures.

\section{Abbreviations}

AED: Antiepileptic drugs; Cl: Confidence interval; ES: Effect size; MRI: Magnetic resonance imaging; QOL: Quality of life

Acknowledgements

Not applicable

\section{Authors' contributions}

$\mathrm{HH}$ and MS contributed in the conception and design of the study, library searches and assembling relevant literature, critical review of the paper, supervising writing of the paper, and database management, and FP and MJM contributed in the data collection, library searches and assembling relevant literature, writing the paper, and critical review of the paper. The authors read and approved the final manuscript.

\section{Funding}

Not applicable

\section{Availability of data and materials}

Please contact author for data requests

Ethics approval and consent to participate

Not applicable

Consent for publication

Not applicable

Competing interests

The authors declare that they have no competing interests.

\section{Author details}

${ }^{1}$ Neurology Department, Zabol University of Medical Sciences, Zabol, Iran. ${ }^{2}$ Mashhad University of Medical Sciences, Mashhad, Iran. ${ }^{3}$ Student Research Committee, Zabol University of Medical Sciences, Zabol, Iran. 
Received: 27 August 2019 Accepted: 26 February 2020

Published online: 12 March 2020

\section{References}

1. Kwan P, Brodie MJ. Early identification of refractory epilepsy. NEJM. 2000 Feb 3;342(5):314-9.

2. Kwan P, Arzimanoglou A, Berg AT, Brodie MJ, Hauser WA, Mathern G,et al. Definition of drug resistant epilepsy. Consensus proposal by the ad hoc task force of the ILAE commission on therapeutic strategies. Epilepsia. 2010;51(9).

3. Engel J, McDermott MP, Wiebe S, Langfitt JT, Stern JM, Dewar S, et al. Early surgical therapy for drug-resistant temporal lobe epilepsy: a randomized trial. Jama. 2012;307(9):922-30.

4. Engel JJ, Wiebe S, French J, Sperling M, Williamson P, Spencer D, et al. Practice parameter: temporal lobe and localized neocortical resections for epilepsy: report of the Quality Standards Subcommittee of the American Academy of Neurology, in association with the American Epilepsy Society and the American Association of Neurological Surgeons. Epilepsia. 2003; 44(6):741-51.

5. Cukiert A, Rydenhag B, Harkness W, Cross JH, Gaillard WD. Task Force for Pediatric Epilepsy Surgery for the ILAE Commissions of Pediatrics and Surgical Therapies. Technical aspects of pediatric epilepsy surgery: report of a multicenter, multinational web-based survey by the ILAE Task Force on Pediatric Epilepsy Surgery. Epilepsia. 2016;57(2):194-200.

6. Berg AT. Epilepsy: efficacy of epilepsy surgery: what are the questions today? Nat Rev Neurol. 2011;7:311-2.

7. Tellez-Zenteno JF, Dhar R, Wiebe S. Long-term seizure outcomes following epilepsy surgery: a systematic review and meta-analysis. Brain. 2005;128: 1188-98.

8. Malmgren K, Sullivan M, Ekstedt G, Kullberg G, Kumlien E. Health-related quality of life after epilepsy surgery: a Swedish multicenter study. Epilepsia. 1997:38:830-8.

9. Engel J Jr. Why is there still doubt to cut it out? Why is there still doubt to cut it out? Epilepsy Curr. 2013;13(5):198-204.

10. Silfvenius H. A global survey on epilepsy surgery, 1980-1990: a report by the Commission on Neurosurgery of Epilepsy, the International League against Epilepsy. Epilepsia (Copenhagen). 1997;38(2):249-55.

11. Schramm J, Behrens E. Surgical and neurological complications in a series of 708 epilepsy surgical procedures. Neurosurgery. 1998;42(3):675-6.

12. Cascino GD, Sharbrough FW, Trenerry MR, Marsh WR, Kelly PJ, So E. Extratemporal cortical resections and lesionectomies for partial epilepsy: complications of surgical treatment. Epilepsia. 1994 Sep;35(5):1085-90.

13. Vakharia VN, Duncan JS, Witt JA, Elger CE, Staba R, Engel J Jr. Getting the best outcomes from epilepsy surgery. Ann Neurol. 2018;83(4):676-90.

14. JENSEN I, Seedorff HH. Temporal lobe epilepsy and neuro-ophthalmology: ophthalmological findings in 74 temporal lobe resected patients. Acta Ophthalmol. 1976;54(6):827-41.

15. Chin PS, Berg AT, Spencer SS, Lee ML, Shinnar S, Sperling MR, et al. Patientperceived impact of resective epilepsy surgery. Neurology. 2006 Jun 27; 66(12):1882-7

16. Eskandar EN, Flaherty A, Cosgrove GR, Shinobu LA, Barker FG II. Surgery for Parkinson disease in the United States, 1996 to 2000: practice patterns, short-term outcomes, and hospital charges in a nationwide sample. J Neurosurg. 2003;99(5):863-71.

17. Gleissner U, Helmstaedter C, Schramm J, Elger CE. Memory outcome after selective amygdalohippocampectomy: a study in 140 patients with temporal lobe epilepsy. Epilepsia. 2002;43(1):87-95.

18. Hamer HM, Morris HH, Mascha EJ, et al. Complications of invasive video-EEG monitoring with subdural grid electrodes. Neurology. 2002;58(1):97-103.

19. Engel J Jr, Wiebe S, French J, Sperling M, Williamson P, Spencer D, et al. Practice parameter: temporal lobe and localized neocortical resections for epilepsy: report of the Quality Standards Subcommittee of the American Academy of Neurology, in association with the American Epilepsy Society and the American Association of Neurological Surgeons. Epilepsia. 2003; 44(6):741-51.

20. French JA. Refractory epilepsy: clinical overview. Epilepsia. 2007:48:3-7.

21. Kuzniecky R, de la Sayette V, Ethier R, Melanson D, Andermann F, Berkovic S, et al. Magnetic resonance imaging in temporal lobe epilepsy: pathological correlations. ANA. 1987;22(3):341-7.

22. Sperling MR, O'Connor MJ, Saykin AJ, Plummer C. Temporal lobectomy for refractory epilepsy. Jama. 1996 Aug 14;276(6):470-5.
23. Liberati A, Altman DG, Tetzlaff J, Mulrow C, Gøtzsche PC, loannidis JP. The PRISMA statement for reporting systematic reviews and meta-analyses of studies that evaluate health care interventions: explanation and elaboration. PLoS medicine. 2009;6(7):e1000100.

24. McGowan J, Sampson M, Salzwedel DM, Cogo E, Foerster V, Lefebvre C. PRESS peer review of electronic search strategies: 2015 guideline statement. JCE. 2016;75:40-6.

25. Vale FL, Reintjes S, Garcia HG. Complications after mesial temporal lobe surgery via inferiortemporal gyrus approach. Neurosurg Focus. 2013;34(6):E2.

26. Heller AC, Padilla RV, Mamelak AN. Complications of epilepsy surgery in the first 8 years after neurosurgical training. Surg Neurol. 2009;71(6):631-7.

27. Rolston JD, Englot DJ, Knowlton RC, Chang EF. Rate and complications of adult epilepsy surgery in North America: analysis of multiple databases. Epilepsy research. 2016 Aug 1;124:55-62.

28. Ozlen F, Asan Z, Tanriverdi T, Kafadar A, Ozkara C, Ozyurt E, Uzan M. Surgical morbidity of invasive monitoring in epilepsy surgery: an experience from a single institution. Turkish neurosurgery. 2010 Jul;20(3):364-72.

29. İpekdal Hi, Karadaş Ö, Erdoğan E, Gökçil Z. Spectrum of surgical complications of temporal lobe epilepsy surgery: a single-center study. Turk Neurosurg. 2011;21(2):147-51.

30. Ahmedov ML, Korkmaz TS, Kemerdere R, Yeni SN, Tanriverdi T. Surgical and neurological complications in temporal lobe epilepsy surgery in modern era. SNI. 2018:9.

31. Hedegärd E, Bjellvi J, Edelvik A, Rydenhag B, Flink R, Malmgren K. Complications to invasive epilepsy surgery workup with subdural and depth electrodes: a prospective population-based observational study. JNNP. 2014; 85(7):716-20.

32. Bjellvi J, Flink R, Rydenhag B, Malmgren K. Complications of epilepsy surgery in Sweden 1996-2010: a prospective, population-based study. Journal of neurosurgery. 2015 Mar 1;122(3):519-25.

33. Binder DK, Podlogar M, Clusmann H, Bien C, Urbach H, Schramm J, et al. Surgical treatment of parietal lobe epilepsy. Journal of neurosurgery. 2009 Jun 1;110(6):1170-8.

34. Lee JH, Hwang YS, Shin JJ, Kim TH, Shin HS, Park SK. Surgical complications of epilepsy surgery procedures: experience of 179 procedures in a single institute. JKNS. 2008:44(4):234.

35. d'Orio P, Pelliccia V, Gozzo F, Cardinale F, Castana L, Russo GL, et al. Epilepsy surgery in patients older than 50 years: effectiveness, safety, and predictors of outcome. Seizure. 2017;50:60-6.

36. Vermeulen L, van Loon J, Theys T, Goffin J, Porke K, Van Laere K, et al. Outcome after epilepsy surgery at the University Hospitals Leuven 19982012. Acta Neurologica Belgica. 2016;116(3):271-8.

37. Mathon B, Navarro V, Bielle F, Nguyen-Michel VH, Carpentier A, Baulac M, et al. Complications after surgery for mesial temporal lobe epilepsy associated with hippocampal sclerosis. World Neurosurg. 2017;102:639-50.

38. Panigrahi M, Vooturi S, Jayalakshmi S. Complications of epilepsy surgery: a single surgeon's experience from South India. World Neurosurg. 2016;91:16-22.

39. Tanriverdi T, Ajlan A, Poulin N, Olivier A. Morbidity in epilepsy surgery: an experience based on 2449 epilepsy surgery procedures from a single institution. Journal of neurosurgery. 2009;110(6):1111-23.

40. Wellmer J, von der Groeben F, Klarmann U, Weber C, Elger CE, Urbach H, et al. Risks and benefits of invasive epilepsy surgery workup with implanted subdural and depth electrodes. Epilepsia. 2012;53(8):1322-32.

41. Srikijvilaikul T. Complications of epilepsy surgery: Prasat Neurological Institute Experiences. JMAT. 2018;101(8):1121-6.

42. Espinoza-Velázquez F, Vázquez-Barrón D. Montes De Oca M, Cuéllar-Herrera M, Velasco AL. Complications of surgical treatment of drug-resistant epilepsy in the General Hospital of Mexico. Rev Mex Neuroci. 2014;15(2):69-73.

43. Dunkley C, Kung J, Scott RC, Nicolaides P, Neville B, Aylett SE, et al. Epilepsy surgery in children under 3 years. Epilepsy Res. 2011;93(2-3):96-106.

44. Jobst BC, Cascino GD. Resective epilepsy surgery for drug-resistant focal epilepsy: a review. JAMA. 2015;313(3):285-93.

45. Engel J, McDermott MP, Wiebe S, Langfitt JT, Stern JM, Dewar S, et al. Early surgical therapy for drug-resistant temporal lobe epilepsy: a randomized trial. JAMA. 2012;307(9):922-30.

46. Hoy D, Brooks P, Woolf A, Blyth F, March L, Bain C. Assessing risk of bias in prevalence studies: modification of an existing tool and evidence of interrater agreement. JCE. 2012:65(9):934-9.

47. Elsharkawy AE, Alabbasi AH, Pannek H, Schulz R, Hoppe M, Pahs G, et al. Outcome of frontal lobe epilepsy surgery in adults. Epilepsy research. 2008 Oct 1;81(2-3):97-106. 
48. Engel JV Jr. Outcome with respect to epileptic seizures. Surg Treat Epilepsies. 1993:609-21.

49. Hosking PG. Surgery for frontal lobe epilepsy. Seizure. 2003;12(3):160-6.

50. Jeha LE, Najm I, Bingaman W, Dinner D, Widdess-Walsh P, Lüders H. Surgical outcome and prognostic factors of frontal lobe epilepsy surgery. Brain. 2007;130(2):574-84.

51. Spencer S, Huh L. Outcomes of epilepsy surgery in adults and children. Lancet Neurol. 2008;7(6):525-37.

52. Schmidt D, Stavem K. Long-term seizure outcome of surgery versus no surgery for drug-resistant partial epilepsy: a review of controlled studies. Epilepsia. 2009 Jun;50(6):1301-9.

53. Seiam AH, Dhaliwal $H$, Wiebe $S$. Determinants of quality of life after epilepsy surgery: systematic review and evidence summary. Epilepsy and Behavior. 2011;21(4):441-5.

54. Wiebe S, Blume WT, Girvin JP, Eliasziw M. A randomized, controlled trial of surgery for temporal-lobe epilepsy. New Engl J Med. 2001;345(5):311-8.

55. De Flon P, Kumlien E, Reuterwall C, Mattsson P. Empirical evidence of underutilization of referrals for epilepsy surgery evaluation. EAN. 2010;17(4):619-25.

56. Englot DJ, Ouyang D, Garcia PA, Barbaro NM, Chang EF. Epilepsy surgery trends in the United States, 1990-2008. Neurology. 2012;78(16):1200-6.

57. Mocco J, Komotar RJ, Ladouceur AK, Zacharia BE, Goodman RR, McKhann GM. Radiographic characteristics fail to predict clinical course after subdural electrode placement. Neurosurgery. 2006;58(1):120-5.

58. Hader WJ, Tellez-Zenteno J, Metcalfe A, Hernandez-Ronquillo L, Wiebe S, et al. Complications of epilepsy surgery-a systematic review of focal surgical resections and invasive EEG monitoring. Epilepsia. 2013 May;54(5):840-7.

\section{Publisher's Note}

Springer Nature remains neutral with regard to jurisdictional claims in published maps and institutional affiliations.

\section{Submit your manuscript to a SpringerOpen ${ }^{\circ}$ journal and benefit from:}

- Convenient online submission

- Rigorous peer review

- Open access: articles freely available online

High visibility within the field

- Retaining the copyright to your article

Submit your next manuscript at $\boldsymbol{\nabla}$ springeropen.com 